\title{
Screening for Ischaemic Heart Disease by Maximal Exercise Testing as part of the Extended Pulhheems Examination - The First 10 Years
}

\author{
Lt Col $\mathrm{N}$ Ineson \\ MRCP(UK), RAMC
}

Consultant Physician

\section{Capt BSF Stacey}

$\mathrm{MB}, \mathrm{ChB}, \mathrm{RAMC}$

$\mathrm{SHO}$ in Medicine

Cardiac Unit, Queen Elizabeth Military Hospital, Stadium Road, Woolwich, London SE18 4QH

SUMMARY: Exercise tests have been an integral part of the extended PULHHEEMS examination since its inception in 1983. In the first 10 years a total of 240 individuals have been examined and $180(75 \%)$ have had normal exercise tests. Individuals with an abnormal test who wished further assessment (58) were subjected to an exercise thallium scan. Of these 36 were normal allowing reassurance of the individual. Of the 22 abnormal scans 15 were subjected to regular follow-up whilst 7 were sufficiently abnormal to merit angiography. Of the seven patients who had angiography one was normal, 3 had significant coronary artery disease and 3 had mitral valve prolapse.

\section{Introduction}

In 1983 a programme of screening medicals for Senior Officers was introduced with the specific aim of risk factor intervention and early detection of Ischaemic Heart Disease (IHD). These medicals involved an extension of the standard army PULHHEEMS medical and became known as Extended PULHHEEMS. An integral part of this medical examination was a symptom limited exercise test. This paper reviews the results of the first 10 years of exercise testing in this selected population.

\section{Methods}

The results of all individuals attending for a standard extended PULHHEEMS during the first 10 years were examined. All individuals had had a full clinical history and examination with particular reference to the risk factors for IHD.

Appropriate advice was given on lifestyle and medical intervention undertaken when necessary.

Following the initial screening medical all participants were exercised on a treadmill to a standard Bruce protocol in a symptom limited maximal exercise test. This was considered positive if chest pain was induced or $2 \mathrm{~mm}$ or more of planar or downsloping ST segment depression at $80 \mathrm{msec}$ beyond the $\mathbf{J}$ point was recorded.

Individuals with abnormal tests were offered further investigation by thallium scintigraphy involving a further exercise test with the injection of $70 \mathrm{MBq}$ of thallium 201 intravenously one minute before stopping the test. The patient was imaged immediately using a Picker/Nuclear Diagnostic Gamma Camera with a high sensitivity collimater. Images were acquired in the anterior, left anterior oblique $45^{\circ}$ and left anterior oblique $70^{\circ}$ positions. After a 3-4 hour rest period images were repeated to compare rest with exercise. Those individuals with multiple or extensive reversible defects were considered for angiography and those with small fixedo defects or evidence of limited reversibility were closelp observed with aggressive risk factor intervention.

The extended PULHHEEMS was initially repeate annually although this was later extended to two yearly.

\section{Results}

Over the 10 year period 240 male subjects have beel screened. The mean age at first examination was 51. years with a range of 46.75 years to 59.9 years. One hundred and eighty $(75 \%)$ had a normal maximum exercise test on initial and any subsequent test. Table $\mathbf{l}$, illustrates the number of exercise tests per individual.

No subjects developed angina during the exercise test although $60(25 \%)$ were electrically positive on a first (40) or subsequent (20) exercise test.

Table 1

Normal Results - examinations per individual

\begin{tabular}{cc}
$\begin{array}{c}\text { Number Extended PULHHEEMS } \\
\text { Examinations }\end{array}$ & Number of subjects \\
\hline 1 & 81 \\
2 & 63 \\
3 & 27 \\
4 & 6 \\
5 & 2 \\
6 & 0 \\
7 & 0 \\
8 & 1 \\
\hline
\end{tabular}

Table 2

Thallium Scan Results

\begin{tabular}{lc}
\hline \multicolumn{1}{c}{ Result of Scan } & Number of subjects \\
\hline Normal & 36 \\
Minor abnormality - observe & 15 \\
Major abnormality - angiography & 7 \\
\hline
\end{tabular}


Table 3

Results of Angiography

\begin{tabular}{lc}
\hline \multicolumn{1}{c}{ Result } & Number of subjects \\
\hline Normal & 1 \\
Mitral Valve Prolapse & 3 \\
Single Vessel Disease & 2 \\
Three Vessel Disease & 1 \\
\hline
\end{tabular}

Of the 60 individuals with positive tests all were offered thallium scans. Two declined this approach preferring to make their own arrangements. Table 2 shows the outcome of the 58 individuals who progressed to a thallium scan - of these scans 22 showed abnormalities with 7 showing significant enough abnormalities to warrant coronary angiography. Table 3 shows the results of angiography. Three individuals had had angiography prior to their inclusion in the extended PULHHEEMS series: One for atypical chest pain which was normal, one for assessment of a previous myocardial infarction and one having had previous angina with a successful single vessel angioplasty. None of these three individuals fell into the group requiring anything more than a standard thallium scan.

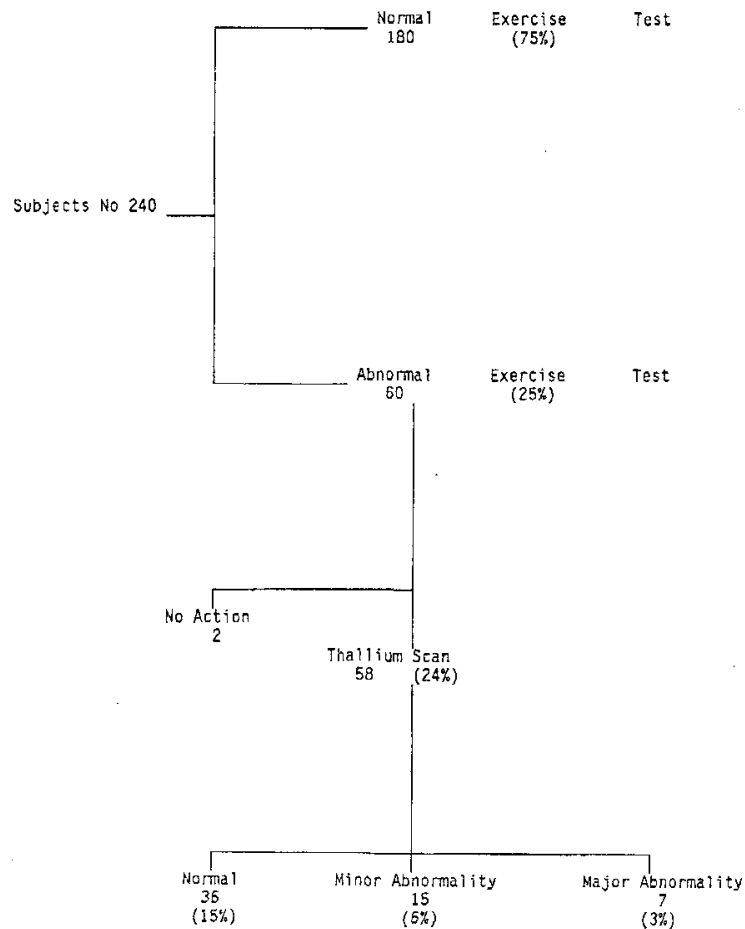

Fig 1. Outcome of Extended Pulhheems

Figure 1 details the total number of patients and their final outcome.

As stated many individuals had multiple examinations due to length of service or follow-up of identified problems. A total of 459 exercise tests were performed of which $356(77.6 \%)$ were normal and $103(22.4 \%)_{3}$ abnormal.

Length of follow-up ranges from 1 year to 10 yearso depending on length of service although the vast majority을 are over 2 years. No comments are made after services? finished. Of the subjects classified as normal by either exercise test or thallium scan none had an adverse $\stackrel{?}{+}$ myocardial event in service defined as development of angina, myocardial infarction or sudden death. One of the fifteen with a minor thallium scan defect sustained a smalluncomplicated inferior infarct. This particular group of $\varrho$ individuals with abnormal thallium scans has been subjection to aggressive risk factor intervention. In the latter years $\overrightarrow{0}$ this has included prophylactic aspirin.

Three individuals have been found to havew asymptomatic significant coronary artery disease. These are again subject to aggressive risk factor intervention and 3 follow-up. One has had an uncomplicated angioplasty.

\section{Discussion}

In terms of IHD the extended PULHHEEMSN examination is designed to assess the major risk factorsc and detect early disease. Risk factor detection is achieved음 by means of a case history examination and blood tes. The treadmill test aims to detect early IHD, eithg asymptomatic or symptomatic.

If a screening programme is to be effective it must acceptable to the individuals concerned and producec results which detect and allow modification of risk factoss for that disease. This is essentially a programme primary and secondary prevention. Both of these aspets are well established in the management of IHD and have resulted in the production of prevention strategy (1-6).

Lynch (7) and Gray (8) have both examined Standard Mortality Rates (SMR) for the army for IHD. Bothō demonstrated a major difference in SMR between the rank structures. In the $1978-84$ period in her 1987 paper Gray reported the SMR for officers was only 50 compared to 140 for other rank servicemen (8).

This data would therefore suggest that the incidence of true IHD would be low amongst our screened population. Our exercise tests produced 60 abnormal individuals out of $240-25 \%$ abnormal.

Having $25 \%$ of the exercise tests positive poses: questions: clearly only a small proportion of these 3 . individuals would be expected to have IHD yet someo would. Exercise tests were conducted as maximal exercise tests with 12 lead analysis and defining ST segmento depression as greater than $2 \mathrm{~mm}$ to be abnormal to reduce false positives. The sensitivity of an exercise test depends으․ on the criteria used to interpret it but is around $70 \%$ with a specificity of $90 \%$ (9), but the predictive value of a positive test is the likelihood that an individual has 0 coronary artery disease. Bayes' theorem of conditional $\underset{\omega}{\mathbb{\omega}}$ probability formally combines the sensitivity, specificity and prevalence of disease in the population tested too 
obtain a predictive value (10). The post test likelihood of disease (predictive value) depends on pretest likelihood (prevalence) of disease in the population tested or from which the patient is taken. A negative test in a group with a low likelihood of disease means that they almost certainly do not have coronary artery disease but similarly a positive test means a significant proportion will be falsely positive.

In our population studied with a relatively low incidence of IHD one is confident that the negative tests are truly negative i.e. $75 \%$ are truly normal. Twenty five per cent however have abnormal exercise tests with a greater risk of coronary artery disease.

In our study of the 60 with positive tests 2 elected to have no further action. These were in individuals close to retirement in the early stages of our screening programme. This left 58 individuals with positive tests and a possibility of underlying IHD. It is these individuals whom we investigated with 201-thallium myocardial scanning.

There is a direct relationship between the presence or extent of jeopardised viable myocardium, i.e. degree and number of areas of reversible ischaemia, and risk of future cardiac events as demonstrated by Brown in 1983 (11). In that study the best predictor of future cardiac events in individuals with previous infarction was the number of myocardial segments with transient defects. Angiography added no significant prognostic value to this non invasive index. Ladenheim et al (12) found that among clinical and scintigraphic variables the number of reversible thallium defects was the best predictor of future events in a large series of patients without known infarction but suspected coronary artery disease. The presence of reversible defects has been shown to have a sixfold to twelvefold increased risk of cardiac death or myocardial infarction compared with normal studies (13). Fleg (14) demonstrated a $48 \%$ event rate in individuals with asymptomatic electrically positive stress tests and abnormal thallium scans over a mean follow-up period of 4.6 years. A very important aspect of the interpretation of thallium scans is the mirror imaging of the above, i.e. a normal thallium study, even in the presence of patients with angiographic coronary artery disease, predicts a very benign outcome $(11,13-19)$. Many clinical series of patients with known or suspected coronary artery disease have therefore consistently shown a very low cardiac event rate among patients with normal thallium studies averaging less than $1 \%$ per year for death or myocardial infarction - an event rate approaching that of the general population in the United States where most of this work has been done (20). The subject of risk factor stratification with thallium scanning is extensively reviewed by Brown (21).

In this study, of the 58 subjects with abnormal exercise tests to be further assessed, 36 had normal thallium scans placing them in a good prognostic group allowing them to be reassured and requiring no further investigation.
Twenty-two subjects had abnormal thallium scans, among whom 15 had minor defects which were felt to need no further action. One of these individuals later sustained a small uncomplicated myocardial infarction. Subsequent angiography revealed single vessel disease which would not normally be subjected to intervention in an asymptomatic individual. All of these 15 patients had more aggressive risk factor intervention and in later years the prescription of prophylactic aspirin.

Seven individuals $(3 \%)$ of the original population had such significant abnormalities that coronary angiography was thought necessary. One was entirely normal representing a true false positive to both exercise test and thallium scan. Three had evidence of mitral valve prolapse angiographically. This condition is well documented as producing false positive imaging (22). In our own review of patients referred for angiography we similarily found a significant number of patients with an abnormal exercise test and thallium scan but normal coronary arteries and mitral valve prolapse at angiography (23). Possible mechanisms to explain thallium defects in patients with normal coronary arteries in mitral valve prolapse include - localised cardiomyopathy producing ischaemia and fibrosis, coronary spasm and coronary embolism from clots on the myxomatous valve (22).

Three patients had abnormal coronary angiograms anc these have been subjected to regular follow-up with one having had a successful coronary angioplasty. Clearly these 3 individuals also had aggressive risk factoo intervention and prophylactic aspirin.

\section{Conclusion}

By a stepped approach it is therefore possible to select out and stratify these individuals for risk factor intervention. It may be argued that an exercise test is not justified in this low risk population. It does however form a valuable assessment of these individuals allowing us to reassure the vast majority with simple risk factor advice. The addition of a thallium scan to those with positive exercise tests allows further risk stratification. The small but nevertheless significant number of individuals with abnormal scans can then be targeted for the most aggressive risk factor intervention, follow-up and consideration of prophylactic aspirin.

\section{REFERENCES}

1. Huermann I, Holme I, Velve Byre K, Leren P. Effect of diet and smoking intervention on the incidence of coronary heart disease: a report from the Oslo Study Group of a randomised trial in healthy men. Lancet 1981; ii: 1303-10.

2. WatTs GF, Lewis B, BRUNT JNH, et al. Effect on coronary artery disease of lipid - lowering diet, or diet plus Cholestyramine, in the St Thomas' Atherosclerosis Regression Study (STARS). Lancet 1992; 339:563-9.

3. Rossouw JE, Lewis B, Rifkind BM. The value of lowering cholesterol after Myocardial Infarction. $N$ Engl J Med 1990; 323:1112-1119. 
4. Lipid Research Clinics Program. The Lipid Research Clinics Coronary Primary Prevention Trial Results I: Reduction in the incidence of coronary heart disease. JAMA: 1984; 251:351-364.

5. Ornish D, Brown SE, SCherwitz LW, et al. Can lifestyle changes reverse coronary artery disease? The Lifestyle Heart Trial. Lancet 1990; 336: 129-33.

6. Department of Health.

The Health of the Nation. A Summary of the Strategy for Health in England. London: HMSO. 1992:

7. LyNCh P and Oleman BJ. Mortality from coronary heart disease in the British Army compared with the civil population. $\mathrm{Br}$ Med J 1981; 283:405-7.

8. GRAY J. Mortality from Ischaemic Heart Disease in the Armed Forces 1973-1984. J R Army Med Corps 1987; 133: 106-112.

9. Ellstead, MH. Stress Testing. Principles and Practice Edition 3. F A Davis Company: 311-312.

10. Diamond GA, ForRester JS. Analysis of probability as an aid in the clinical diagnosis of coronary artery disease. N Engl J Med 1979; 300:1350-8.

11. Brown KA, Boucher CA, OKada RD, et al. Prognostic Value of Exercise Thallium - 201 Imaging in patients presenting for evaluation of chest pain. $J$ Am Coll Cardiol 1983; 1:994-1001.

12. Ladenheim ML, Pollock BH, Rozanski A, et al. Extent and Severity of myocardial hypo-perfusion as predictors of prognosis in patients with suspected coronary artery disease. J Am Coll Cardiol 1986; $7: 464-471$.

13. Stanlloff HM, Forrester JS, Berman DS, Swan HJC. Prediction of death, myocardial infarction, and worsening chest pain using thallium scintigraphy and exercise electrocardiography. J Nucl Med 1986; 27:1842-1848.

14. Fleg JL, Gerstenblith G, Zonderman AB, et al. Prevalence and prognostic significance of exercise induced silent myocardial ischaemia detected by thallium scintigraphy and electrocardiography in asymptomatic volunteers. Circulation 1990; 81:428436.
15. Iskandrian AS, HaKki AH, Kane-Marsch S Prognostic implications of exercise thallium - $20 \xi$ scintigraphy in patients with suspected or know coronary artery disease. Am Heart $J$ 1985; 110:135尺 143.

16. Iskandrian AS, Hakki AH, Kane-Marsch S: Exercise thallium - 201 scintigraphy in men wit? nondiagnostic exercise electrocardiograms Prognostic implications. Arch Intern Med 1986; 146 2189-2193.

17. Kaul S, Finkelstein DM, Homma $\mathrm{S}$, et a Superiority of quantitative exercise thallium $-20 \vec{P}$ variables in determining long-term prognosis i⿸\zh14⿰⿺乚一匕 ambulatory patients with chest pain: A comparisoi with cardiac catherization. J Am Coll Cardiol 1988 12:25-34.

18. Wahl JM, Hakki AH, Iskandrian AS. Prognostic implications of normal exercise thallium - 20 N images. Arch Intern Med 1985; 145:253-256.

19. Heo J, Thompson WO, Iskandrian AS. Progno implications of normal exercise thallium images. J Noninvas Cardiol 1987; 1:209-212.

20. National Center for Health Statistics. Vital statis $\mathbb{E c} \overrightarrow{0}$ of the United States, 1979: Vol II, Mortality Part8A? Washington, DC, US Government Printing Offe DHHS Publication No (PHS) 84-1101, 1984.

21. Brown AK. Prognostic Value of Thallium - 20 跑 Myocardial Perfusion Imaging. A Diagnostic Too Comes of Age. Circulation 1991; 83:363-381.

22. Butman S, Chandraratna P, Milne N, et al. Stres Myocardial Imaging in Patients with Mitral Valve Prolapse: Evidence of a Perfusion Abnormality Cathet Cardiovasc Diagn 1982; 8:243-252.

23. Kiltie AE, Ineson N. Army Cardiac Unit - Cardiae Catheter Patients, 1991 - A Review. J R Army Me Corps 1994; 140:79-85. 